\title{
Predicting Ischemic Risk Using Blood Oxygen Level- Dependent MRI in Children with Moyamoya
}

\author{
(D) N. Dlamini, (D) M. Slim, (DF. Kirkham, (D). Shroff, (D). Dirks, (D) M. Moharir, (DD. MacGregor, (D)A. Robertson, (D). deVeber, \\ and iDW. Logan
}

\begin{abstract}
BACKGROUND AND PURPOSE: Moyamoya is a progressive steno-occlusive arteriopathy. MR imaging assessment of cerebrovascular reactivity can be performed by measuring the blood oxygen level-dependent cerebrovascular reactivity response to vasoactive stimuli. Our objective was to determine whether negative blood oxygen level-dependent cerebrovascular reactivity status is predictive of ischemic events in childhood moyamoya.
\end{abstract}

MATERIALS AND METHODS: We conducted a retrospective study of a consecutive cohort of children with moyamoya who underwent assessment of blood oxygen level-dependent cerebrovascular reactivity. The charts of patients with written informed consent were reviewed for the occurrence of arterial ischemic stroke, transient ischemic attack, or silent infarcts. We used logistic regression to calculate the $\mathrm{OR}$ and $95 \% \mathrm{Cl}$ for ischemic events based on steal status. Hazard ratios for ischemic events based on age at blood oxygen level-dependent cerebrovascular reactivity imaging, sex, and moyamoya etiology were calculated using Cox hazards models.

RESULTS: Thirty-seven children (21 female; median age, 10.7 years; interquartile range, 7.5-14.7 years) were followed for a median of 28.8 months (interquartile range, 13.7-84.1 months). Eleven (30\%) had ischemic events, $82 \%$ of which were TIA without infarcts. Steal was present in 15 of $16(93.8 \%)$ hemispheres in which ischemic events occurred versus 25 of $58(43.1 \%)$ ischemic-free hemispheres (OR $=19.8 ; 95 \% \mathrm{Cl}, 2.5-160 ; P=.005)$. Children with idiopathic moyamoya were at significantly greater risk of ischemic events (hazard ratio, 3.71; 95\% $\mathrm{Cl}, 1.1-12.8 ; P=.037)$.

CONCLUSIONS: Our study demonstrates that idiopathic moyamoya and the presence of steal are independently associated with ischemic events. The use of blood oxygen level-dependent cerebrovascular reactivity could potentially assist in the selection of patients for revascularization surgery and the direction of therapy in children with moyamoya.

ABBREVIATIONS: BOLD = blood oxygen level-dependent; $\mathrm{CVR}=$ cerebrovascular reactivity; $\mathrm{HR}=$ hazard ratio; IQR = interquartile range

M oyamoya is a chronic progressive steno-occlusive arteriopathy, which typically involves the distal internal carotid artery and/or the proximal anterior cerebral and middle cerebral arteries of the circle of Willis, leading to the development of a compensatory vascular network at the base of the brain. ${ }^{1,2}$ In childhood, moyamoya is associated with a greater risk of recurrent ischemic

Received July 5, 2019; accepted after revision October 2.

From the Division of Neurology (N.D., M. Slim, M.M., D.M., A.R., G.d.V., W.L.), Department of Pediatrics, and Departments of Diagnostic Imaging (M. Shroff) and Surgery (P.D.), The Hospital for Sick Children, Toronto, Ontario, Canada; and Developmental Neurosciences Unit and Biomedical Research Centre (F.K.), University College London Great Ormond Street Institute of Child Health, London, UK.

This study was funded by the Auxilium Foundation.

G. deVeber and W. Logan are Co-Senior Authors.

Please address correspondence to Nomazulu Dlamini, MD, MSc, PhD, Division of Neurology, The Hospital for Sick Children, 555 University Ave, Toronto, ON, Canada M5G 1X8; e-mail: nomazulu.dlamini@sickkids.ca

http://dx.doi.org/10.3174/ajnr.A6324 strokes and poor neurologic outcomes, which result in a substantial and sustained economic burden to the family and society. ${ }^{3,4}$ There is no cure for the disease, and medical therapeutic strategies are thus far inadequate at preventing the adverse outcomes associated with moyamoya. Surgical revascularization, the mainstay of treatment, has been shown to be effective in improving cerebral blood flow and reducing ischemic risk in children with moyamoya. ${ }^{5}$ However, multiple factors need to be considered when determining the appropriateness and timing of surgical interventions, including disease severity, risk of ischemic events, perioperative risk, technical aspects of vascular surgery, and anesthesia risk. ${ }^{6-9}$

Cerebrovascular reactivity (CVR) is defined as the measurement of vessel reactivity in response to a vasoactive stimulus such as carbon dioxide. It is an important marker of cerebrovascular reserve and autoregulation through which cerebral blood flow is maintained under physiologic conditions of stress such as hypotension and anemia. ${ }^{10-12}$ 
Harnessing the paramagnetic properties of deoxygenated hemoglobin, blood oxygen level-dependent (BOLD) MR imaging can be used to perform in vivo assessment of cerebrovascular reactivity and reserve by measuring the change in BOLD-MR imaging signal in response to a hypercapnic-vasoactive challenge. ${ }^{13-15}$ Negative BOLD-CVR, referred to as "vascular steal", occurs when blood flow redistributes away from the corresponding vascular territory during the global vasodilatory stimulus. Impairment of CVR and negative BOLD reactivity or steal in adults with arteriopathy are independent predictors of ischemic risk, including stroke and TIA. ${ }^{16-18}$ Hence, the demonstration of steal is used to identify adult patients with moyamoya who might benefit from revascularization surgery. ${ }^{19,20}$ However, any association between steal and ischemic risk has not been demonstrated in children. Early diagnosis of children with moyamoya before symptomatic ischemic presentation now occurs as a result of increased syndrome-specific MR imaging screening protocols. The incidence of ischemic events is reported to peak between 5 and 10 years, and the risk of recurrent ischemic events after the first ischemic presentation is high. ${ }^{21-23}$ The need for improved risk-stratification for the direction of care forms the basis of the compelling need for a clinically useful tool for the prediction of ischemic risk in children with moyamoya. An MR imaging-based biomarker of ischemic risk using standard MR images has the potential to be such a tool and to provide a noninvasive, individualized approach to the selection of pediatric patients for revascularization surgery.

We hypothesized that negative BOLD-CVR status or steal is a predictor of ischemic risk in children with moyamoya.

\section{MATERIALS AND METHODS}

\section{Population and Study Definitions}

We conducted a retrospective study of a consecutive cohort of children with moyamoya who underwent BOLD-CVR assessment and were followed in our clinic between November 2000 and September 2017. We included children 1-18 years of age, diagnosed according to Fukui criteria and confirmed by conventional angiography. ${ }^{24}$ Children with unilateral moyamoya and collaterals were included in the study. Children without a comorbid condition were diagnosed as having idiopathic moyamoya. Children with comorbid neurofibromatosis type 1, sickle cell disease, trisomy 21, other chromosomal conditions, or radiation vasculopathy were diagnosed as having moyamoya. Demographic data, clinical characteristics, and treatment modalities were reviewed for all eligible patients.

Ethics permission was obtained from the institutional research ethics board at The Hospital for Sick Children, and written informed consent was obtained from all study participants.

\section{Study Outcomes}

Our primary outcome was the occurrence or recurrence of ipsilateral ischemic events following BOLD-CVR imaging evaluation. Patient charts were reviewed for the occurrence of any of the following: arterial ischemic stroke, TIA, or silent infarcts. Arterial ischemic stroke was defined as the occurrence of a focal neurologic deficit with radiologic evidence of new focal areas of infarction on neuroimaging within a vascular territory. TIA was defined as the occurrence of transient focal neurologic deficits lasting $<24$ hours, without radiologic evidence of new focal areas of infarction and which were not seizures or migraines clinically. Silent infarcts were defined as the presence of new focal areas of infarction on neuroimaging in the absence of a clinically evident focal neurologic deficit.

\section{MR Imaging Acquisition}

MR imaging was performed on a $1.5 \mathrm{~T}$ or $3 \mathrm{~T}$ scanner (Achieva; Philips Healthcare, Best, the Netherlands). Anatomic imaging included standard fluid-attenuated inversion recovery, diffusionweighted imaging, and 3D time-of-flight MRA. High-resolution 3D T1-weighted structural images [160 slices; voxel size $=(0.86-$ 1) $\left.\times(0.86-1) \times(1-2) \mathrm{mm}^{3} ; \mathrm{FOV}=22-26 \mathrm{~cm}\right]$ were acquired for tissue classification and coregistration of the CVR maps.

\section{Cerebrovascular Reactivity Imaging Acquisition}

Vasoactive stimulation was achieved by hypercapnic challenge using breath-hold or targeted controlled delivery of carbon dioxide in children older than 7 years of age and ventilator-assisted delivery of carbon dioxide under general anesthetic in children younger than 7 years of age during CVR acquisition..$^{15,25,26}$ CVR data were acquired using a $\mathrm{T} 2^{\star}$-weighted single-shot echo-planar gradient-echo sequence ( 25 slices; TE, 30-40 ms; TR, $2000 \mathrm{~ms}$; flip angle, $90^{\circ}$; FOV , $22-26 \mathrm{~cm}$; matrix, $64 \times 64$; section thickness, $5 \mathrm{~mm}$; dynamics, 180-240).

\section{Cerebrovascular Reactivity Postprocessing}

Blood oxygen level-dependent MR imaging processing and the generation of CVR maps were conducted using Analysis of Functional Neuro Images (AFNI; http://afni.nimh.nih.gov/afni), ${ }^{27,28}$ the FMRIB Software Library (FSL; http://www.fmrib.ox.ac.uk/fsl), ${ }^{29-31}$ and custom scripts. The first 2 volumes were dropped for scanner stabilization, and the data were section-time- and motion-corrected. The maximum displacement, which is the maximum distance for each volume from a reference volume during the registration, was calculated. The maximum distance signal was regressed from the data, and volumes with a maximum distance exceeding $1.5 \mathrm{~mm}$ were censored. Data were smoothed using a 7-mm full width at half maximum Gaussian kernel, normalized to a mean intensity of 10,000 , and temporally filtered between 0.001 and $0.2 \mathrm{~Hz}$. Patients' functional data were registered to the Montreal Neurological Institute space using each patient's high-resolution T1 image. Signal contributions from the CSF, along with the 6 motion parameters, were regressed from the data as covariates in a generalized linear model.

For CVR maps, the patient's BOLD time-series in each voxel of the brain was subjected to generalized linear model analysis using the corresponding averaged cerebellar time courses as a regressor. The regression coefficients (or the $\beta$ weights) were then calculated for each voxel. Negative $\beta$ weights describing an inverse relationship with the regressor are the markers of steal. CVR maps consisting of voxelwise negative and positive $\beta$ weights (describing a negative and positive relationship with the regressor, respectively) were coregistered to the high-resolution T1 images in the native space for visualization. ${ }^{15,32}$

Visual inspection of the BOLD-CVR maps for hemispheric negative reactivity/steal was conducted by study neurologists blinded to the clinical information (Fig 1). The interrater 

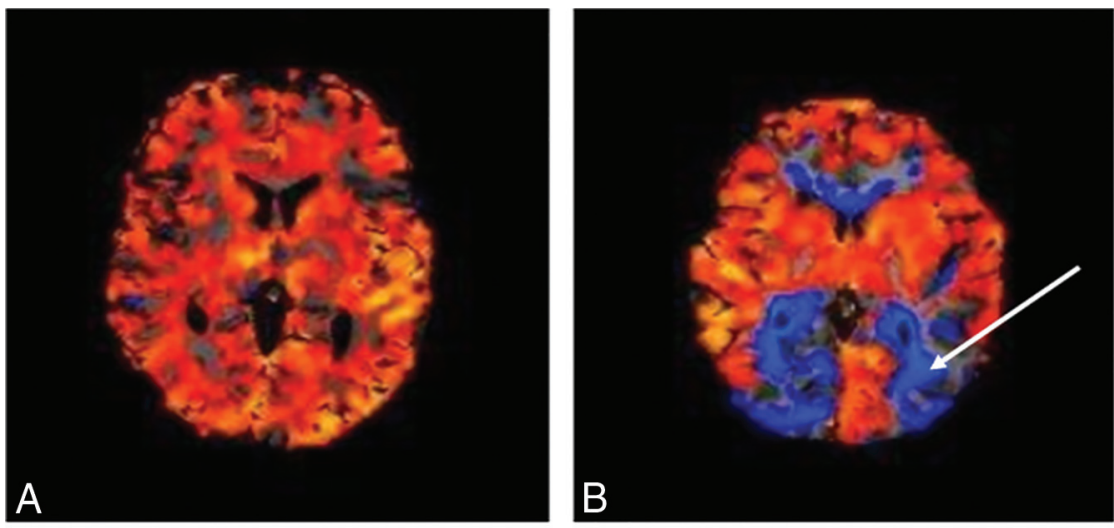

$-10$

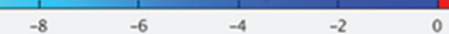

FIG 1. Representative BOLD-CVR parametric maps demonstrating normal (positive) $(A)$ reactivity and abnormal (negative) reactivity ( $B$, arrow).

Table 1: Baseline clinical and demographic characteristics

\begin{tabular}{|c|c|}
\hline & $\begin{array}{l}\text { Total Sample } \\
(n=37)\end{array}$ \\
\hline \multicolumn{2}{|l|}{ Demographic characteristics } \\
\hline Female (No.) (\%) & $21(56.8)$ \\
\hline $\begin{array}{l}\text { Age at moyamoya diagnosis (median) (IQR, } \\
25-75)(y r)\end{array}$ & $10(6.3-11.8)$ \\
\hline Age at initial CVR (median) (IQR, 25-75) (yr) & $10.7(7.5-14.7)$ \\
\hline Time to follow-up (median) (IQR, 25-75) (mo) & $20.8(13.7-84.1)$ \\
\hline \multicolumn{2}{|l|}{ Moyamoya classification } \\
\hline Idiopathic & $14(37.8)$ \\
\hline Syndromic & $23(62.2)$ \\
\hline NFI & $9(24.3)$ \\
\hline Trisomy 21/other chromosomal disorders & 7 (18.9) \\
\hline Sickle cell disease & $5(13.5)$ \\
\hline Postradiation vasculopathy & $2(5.4)$ \\
\hline \multicolumn{2}{|l|}{ Clinical presentation } \\
\hline Stroke (No.) (\%) & $12(32.4)$ \\
\hline Bilateral & $2(5.4)$ \\
\hline Right & $6(16.2)$ \\
\hline Left & $4(10.8)$ \\
\hline TIA (No.) (\%) & $8(21.6)$ \\
\hline Seizure (No.) (\%) & $3(8)$ \\
\hline Headaches (No.) (\%) & $8(21.6)$ \\
\hline Asymptomatic (No.) (\%) & $6(16.2)$ \\
\hline Other (No.) (\%) & $2(5.4)$ \\
\hline \multicolumn{2}{|l|}{ Radiographic findings (No.) (\%) } \\
\hline \multicolumn{2}{|l|}{ Parenchymal } \\
\hline Not ischemic & $8(21.6)$ \\
\hline Watershed & $12(32.4)$ \\
\hline Deep white matter & $1(2.7)$ \\
\hline Cortical & $12(32.4)$ \\
\hline Cortical & $3(8.1)$ \\
\hline Cortical ischemic and watershed & $14(37.8)$ \\
\hline \multicolumn{2}{|l|}{ Vascular } \\
\hline \multicolumn{2}{|l|}{ Moyamoya laterality (No.) (\%) } \\
\hline Left & $8(21.6)$ \\
\hline Right & $6(16.2)$ \\
\hline Bilateral & $23(62.2)$ \\
\hline \multicolumn{2}{|l|}{ Grade of stenosis (No.) (\%) } \\
\hline $50 \%-74 \%$ Occlusion & $5(13.5)$ \\
\hline$\geq 75 \%$ Occlusion & $32(86.5)$ \\
\hline
\end{tabular}

Note:-NF1 indicates neurofibromatosis type 1. reliability for the hemispheric scoring by visual inspection was substantial (weighted $\kappa$ of 1 for the left side and 0.83 for the right side). ${ }^{15}$

\section{Statistical Analysis}

Continuous variables were presented as medians and interquartile ranges (IQRs). Qualitative variables were described using frequency distributions and proportions. Patient characteristics were compared using the Mann-Whitney $U$ test or Fisher exact test, as appropriate.

The evaluation of the ischemic risk as a function of steal status was conducted per hemisphere. ${ }^{33,34}$ In children who had multiple BOLD-CVR assessments during the study period, the BOLD-CVR study before the occurrence of ischemic events or the end of the study follow-up was considered. We used logistic regression to calculate the OR and 95\% CI for ischemic risk based on BOLD-CVR steal status. To control for the effects of surgical interventions, we used multivariable logistic models that controlled for procedures undertaken in the corresponding hemispheres.

Hazard ratios (HRs) and the corresponding 95\% CIs for ischemic events at the patient level (ie, occurring in any of 2 hemispheres) as function of age at initial BOLD-CVR imaging (dichotomized into 8 years of age and younger and older than 8 years of age), ${ }^{35,36}$ sex, and moyamoya etiology were calculated by using Cox proportional hazards models. The compliance with the proportional hazards assumption was assessed using the scaled Schoenfeld residuals and by visual inspection of the log (minus $\log$ ) curves for the different Cox models. $P<.05$ was statistically significant. Statistical analyses were conducted using $\mathrm{R}$ statistical and computing software, Version 3.4.1 (http://www.r-project.org).

\section{RESULTS}

\section{Population Description}

Thirty-seven children (21 female; median age, 10.7 years; IQR, $7.5-14.7$ years) were included in the study (Table 1 ). The median age at moyamoya diagnosis was 9.9 years (IQR, 6.3-11.8 years). Twelve (32\%) presented with arterial ischemic stroke; $8(22 \%)$, TIAs (without infarction); 6 (16\%) were asymptomatic; 8 (21.6\%) had headaches only; and $3(8 \%)$, seizures. Twenty-eight children (76\%) were treated with aspirin; 4 children were on chronic blood transfusion; 1 child had a bone marrow transplant; and another underwent radiation therapy and chemotherapy during the study period. Twenty-one children had revascularization surgery before (7; 19\%) or following $(14 ; 38 \%)$ enrollment and before the study end point.

\section{Steal Status and Baseline Clinical and Demographic Characteristics}

Twenty-five children had steal in at least 1 hemisphere on BOLD-CVR imaging. Thirty-seven of 74 hemispheres had steal: 
Table 2: Comparison of clinical and demographic characteristics based on steal status ${ }^{a}$ and ischemic events

\begin{tabular}{|c|c|c|c|c|c|c|}
\hline & \multicolumn{2}{|c|}{ Steal Status ${ }^{a}$} & \multirow[b]{2}{*}{$P$ Value } & \multicolumn{2}{|c|}{ Ischemic Events } & \multirow[b]{2}{*}{$P$ Value } \\
\hline & No Steal $(n=12)$ & Steal $(n=25)$ & & No $(n=26)$ & Yes $(n=11)$ & \\
\hline Age at baseline CVR (median) (IQR, 25-75) (yr) & $9.3(5.6-14.5)$ & $10.8(8.3-15)$ & .28 & $10.9(8.3-15)$ & $10.3(7.2-12.5)$ & .44 \\
\hline Female (No.) (\%) & $5(41.7)$ & $16(64)$ & .29 & $14(53.9)$ & $7(63.6)$ & .72 \\
\hline Moyamoya classification (No.) (\%) & & & 69 & & & .06 \\
\hline Idiopathic & $4(33.3)$ & $10(40)$ & & $7(26.9)$ & $7(63.6)$ & \\
\hline Syndromic ${ }^{\mathrm{b}}$ & $8(66.7)$ & $15(60)$ & & $19(73.1)$ & $4(36.4)$ & \\
\hline NFI & $2(16.7)$ & $7(28)$ & & 7 (26.9) & $2(18.2)$ & \\
\hline Trisomy 21/other chromosomal disorders & $3(25)$ & $4(16)$ & & $6(23.1)$ & $1(9.1)$ & \\
\hline Sickle cell disease & $1(8.3)$ & $4(16)$ & & $4(15.4)$ & $1(9.1)$ & \\
\hline Postradiation vasculopathy & $2(16.7)$ & 0 & & $2(7.7)$ & 0 & \\
\hline Stroke (No.) (\%) & $4(33.3)$ & $8(32)$ & 1 & $11(42.3)$ & $1(9.1)$ & .06 \\
\hline TIA (No.) (\%) & $2(16.7)$ & $6(24)$ & 1 & $5(19.2)$ & $3(27.3)$ & .67 \\
\hline Seizure (No.) (\%) & $2(16.7)$ & $1(4)$ & .24 & $2(7.7)$ & $1(9.1)^{\prime}$ & 1 \\
\hline Headaches (No.) (\%) & $3(25)$ & $5(20)$ & 1 & $6(23.1)$ & $2(18.2)$ & 1 \\
\hline Asymptomatic (No.) (\%) & $2(16.7)$ & $4(16)$ & 1 & $3(11.5)$ & $3(27.3)$ & .33 \\
\hline Others (No.) (\%) & 0 & $2(8.3)$ & .54 & 0 & $2(18.2)$ & .08 \\
\hline Moyamoya laterality (No.) (\%) & & & .77 & & & .78 \\
\hline Left & $3(25)$ & $5(20)$ & & $6(23.1)$ & $2(18.2)$ & \\
\hline Right & $1(8.3)$ & $5(20)$ & & 5 (19.2) & $1(9.1)$ & \\
\hline Bilateral & $8(66.7)$ & $15(60)$ & & 15 (57.7) & $8(72.7)$ & \\
\hline
\end{tabular}

Note:-NF1 indicates neurofibromatosis type 1.

${ }^{a}$ Steal status before ischemic event occurrence or the end of follow-up.

${ }^{b}$ Comorbidities falling under syndromic moyamoya are shown for informative purposes only and were not included in the inferential analysis.

17 (23\%) left and 20 (27\%) right hemispheres. Comparisons of clinical and demographic characteristics of patients with steal in at least 1 hemisphere versus those with no steal are summarized in Table 2. Patients with steal were more likely to experience ischemic events compared with those with no steal (36\% versus $16.7 \%$ ). They were more likely to be female (64\% versus $41.7 \%$ ) and be diagnosed with idiopathic moyamoya (40\% versus $33.3 \%$ ) (Table 2).

\section{Predictors of Ischemic Events}

During a median follow-up of 28.8 months (IQR, 13.7-84.1 months), ischemic events were documented in 11 children: 1 with arterial ischemic stroke, 9 with TIA without infarcts, and 1 with asymptomatic silent infarction. Five children had bilateral, 4 had left-sided, and 2 had right-sided ischemic events. No significant differences in clinical and demographic characteristics were found between children who had ischemic events and those who did not (Table 2).

Between-group comparisons of hemispheric steal status by ipsilateral hemispheric ischemic event status demonstrated the presence of steal in 15 of 16 (93.8\%) hemispheres in which ischemic events occurred versus 25 of 58 (43.1\%) ischemic-free hemispheres $(\mathrm{OR}=19.8 ; 95 \% \mathrm{CI}, 2.5-160 ; P=.005)$. When adjusted for surgical interventions in the corresponding hemisphere, the odds of ischemic events remained significantly higher among hemispheres with steal ( $\mathrm{OR}=19.9 ; 95 \% \mathrm{CI}, 2.45-161 ; P=.005)$.

Univariable analysis using the Cox proportional hazards model demonstrated that children with idiopathic moyamoya were at significantly greater risk of ischemic events $(\mathrm{HR}=3.71$; 95\% CI, 1.1-12.8; $P=.03$ ) (Fig 2). Age as a continuous variable was not predictive of ischemic events. Older age (older than 8 years) and male sex were suggestive of a lower risk of ischemic events, though statistical significance was not reached (Fig 2). On controlling for age and sex, the association of ischemic risk with idiopathic moyamoya remained statistically significant $(\mathrm{HR}=$ 3.95; 95\% CI, 1.12-13.9; $P=.03$ ). There were no violations of the proportional hazards assumption in any of these models.

\section{DISCUSSION}

Our study suggests an association between BOLD-CVR steal status, idiopathic moyamoya and an increased risk of ischemic events in childhood moyamoya. Almost two-thirds of the children with moyamoya had steal. Children with steal were more likely to be female, diagnosed with idiopathic moyamoya, and experience ischemic events. The presence of steal was associated with an increased risk of ischemic events in the corresponding hemisphere, which is similar to findings in studies in adults with arteriopathy. ${ }^{17,18}$ To our knowledge, this is the first study to investigate the association between steal status and ischemic risk in children with arteriopathy.

In a large single-center study of asymptomatic children with syndromic moyamoya, radiographic progression occurred in most and typically heralded clinical progression. ${ }^{37}$ Children with sickle cell disease had a higher risk of radiographic and clinical progression than children with neurofibromatosis type 1 , and those with unilateral moyamoya had the lowest overall rate of progression. In our study, there were no differences in clinical characteristics between the steal and no-steal or the ischemic and no ischemic event groups, highlighting the limitations of current clinical approaches for the assessment of ischemic risk in this population. Our study showed that children with steal had significantly higher ipsilateral ischemic risk. The odds for ischemic events remained significantly elevated for children with steal after controlling for revascularization surgery conducted in the respective hemispheres.

The current understanding of the natural history and stroke risk profile of idiopathic moyamoya is mostly derived from studies in Asian populations, which describe a bimodal stroke-risk profile of ischemic stroke typically occurring in 

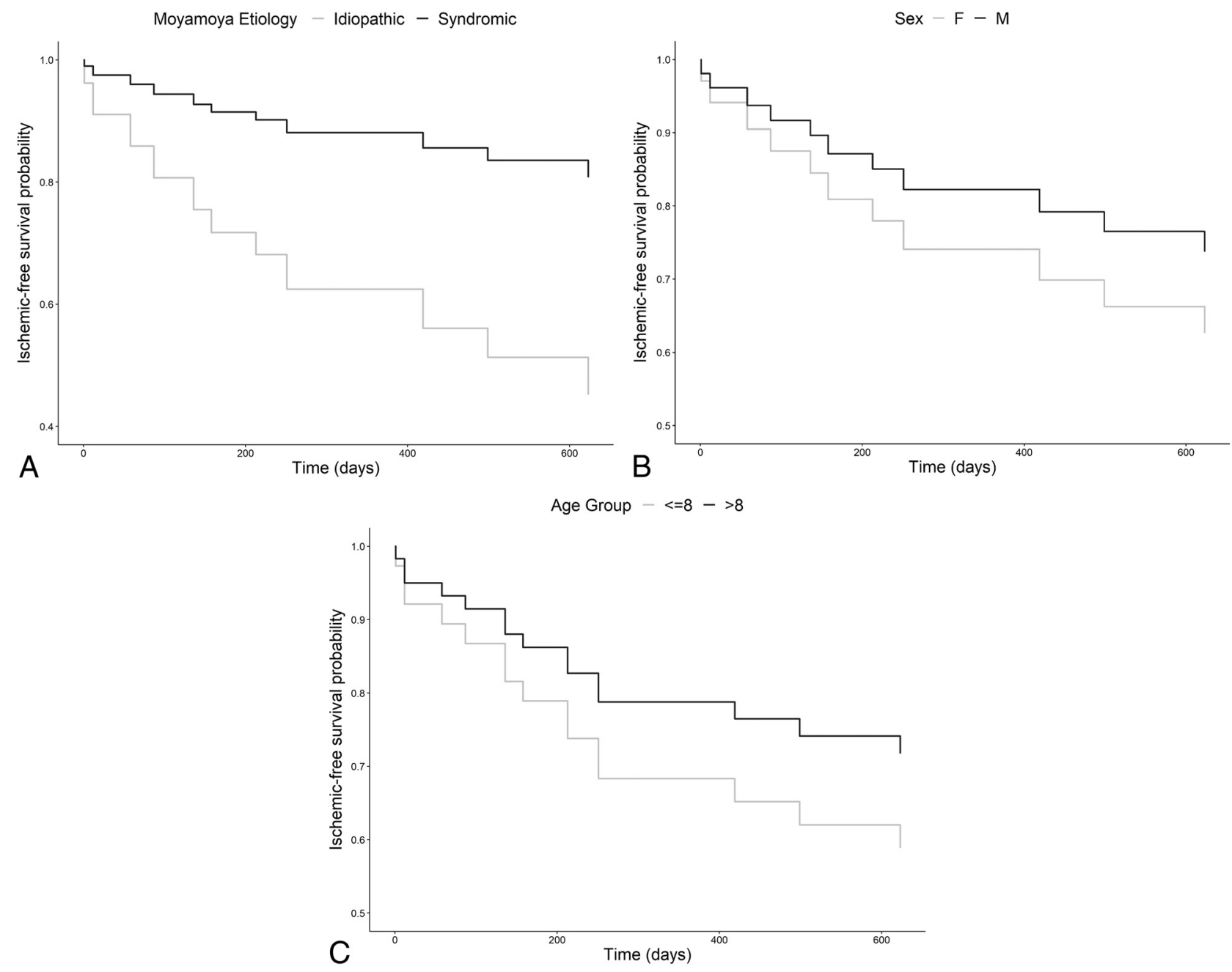

FIG 2. Direct adjusted survival curves for ischemic-free survival as a function of the moyamoya comorbidities (A) (HR for idiopathic moyamoya: 3.71; 95\% Cl, 1.1-12.8; $P=.03$ ), sex (B) (HR for males: $0.65 ; 95 \% \mathrm{Cl}, 0.19-2.23 ; P=.49$ ), and age group (C) (HR for older than 8 years: 0.62 ; $95 \% \mathrm{Cl}$, $0.18-$ 2.1; $P=.44)$. Age as a continuous variable was not predictive of ischemic events. Age is represented in years.

the first decade of childhood and hemorrhagic syndromes dominating in adulthood. ${ }^{24}$ In a recently published cross-sectional study of a large international cohort of children with predominantly syndromic moyamoya, older age was also linked to a lower ischemic risk. ${ }^{38}$ Similarly, in our study, older children had lower ischemic risk, but these results did not reach statistical significance. While no significant differences in the ischemic risk between patients with idiopathic or syndromic moyamoya were reported, our longitudinal analysis using Cox regression models demonstrated significantly higher ischemic risk associated with a diagnosis of idiopathic moyamoya.

Hence, BOLD-CVR studies using standard T2* gradient-echo sequences could potentially allow quantifiable clinical assessment of ischemic risk and the subsequent prediction of future ischemic events in children with moyamoya. The clinical correlates of BOLD-CVR-detected steal are pertinent to and important for an improved individualized model of care for children with moyamoya.

Limitations of our study include the small sample size, limiting our statistical analysis. ${ }^{39}$ However, to our knowledge, this is the largest single-center North American study examining a functional MR imaging technique for the prediction of ischemic risk in childhood moyamoya. BOLD-CVR studies were systematically conducted at predetermined time points according to institutional practice guidelines in most study participants. Consequently, we were unable to determine the temporal relationship between subclinical ischemic MR imaging changes and changes in steal status. However, this issue reflects real-world clinical practice. With the wider acceptance and implementation of BOLD-CVR studies in the longitudinal follow-up of children with moyamoya, future directions will include qualitative and quantitative predictive analyses of a larger prospective cohort. ${ }^{15,40}$ However, the purpose of this study was to evaluate whether qualitative analysis of BOLD-CVR maps could be used as a biomarker of ischemic risk in childhood moyamoya and thus be translatable for clinical use.

\section{CONCLUSIONS}

Our study demonstrated that the presence of steal was associated with significantly greater odds of developing ipsilateral ischemic 
events. Furthermore, idiopathic moyamoya etiology was predictive of ischemic events. The use of hypercapnic challenge BOLDCVR in combination with other clinical predictors in children with moyamoya represents a promising model for the clinical assessment of ischemic risk and patient selection for revascularization surgery. Larger prospective clinical studies are warranted to adequately elucidate the clinical utility of BOLD-CVR in predicting ischemic risk in this high-risk population.

Disclosures: Fenella Kirkham—UNRELATED: Consultancy: Shire Pharmaceuticals Group, Eisai, BIAL, Pharmaceuticals, Comments: for work on epilepsy; Employment: University College London Great Ormond Street Institute of Child Health Institute of Child Health, University of Southampton; Grants/Grants Pending: Action Medical Research (UK charity), Comments: for a trial of montelukast in sickle cell disease*; Royalties: MacKeith press. *Money paid to the institution.

\section{REFERENCES}

1. Suzuki J, Takaku A. Cerebrovascular "Moyamoya” disease: disease showing abnormal net-like vessels in base of brain. Arch Neurol 1969;20:288-99 CrossRef Medline

2. Fukui M, Kono S, Sueishi K, et al. Moyamoya disease. Neuropathology 2000;20(Suppl):S61-64 Medline

3. Amlie-Lefond C, Bernard TJ, Sebire G, et al. Predictors of cerebral arteriopathy in children with arterial ischemic stroke: results of the International Pediatric Stroke Study. Circulation 2009;119:1417-23 CrossRef Medline

4. Gardner MA, Hills NK, Sidney S, et al. The 5-year direct medical cost of neonatal and childhood stroke in a population-based cohort. Neurology 2010;74:372-78 CrossRef Medline

5. Scott RM, Smith ER. Moyamoya disease and Moyamoya syndrome. N Engl J Med 2009;360:1226-37 CrossRef Medline

6. Soriano SG, Sethna NF, Scott RM. Anesthetic management of children with Moyamoya syndrome. Anesth Analg 1993;77:1066-70 CrossRef Medline

7. Imaizumi T, Hayashi K, Saito K, et al. Long-term outcomes of pediatric Moyamoya disease monitored to adulthood. Pediatr Neurol 1998;18:321-25 CrossRef Medline

8. Kim SK, Seol HJ, Cho BK, et al. Moyamoya disease among young patients: its aggressive clinical course and the role of active surgical treatment. Neurosurgery 2004;54:840-44; discussion 44-46 Medline

9. Heyer GL, Dowling MM, Licht DJ, et al. The cerebral vasculopathy of PHACES syndrome. Stroke 2008;39:308-16 CrossRef Medline

10. Harper AM, Glass HI. Effect of alterations in the arterial carbon dioxide tension on the blood flow through the cerebral cortex at normal and low arterial blood pressures. J Neurol Neurosurg Psychiatry 1965;28:449-52 CrossRef Medline

11. Kety SS, Schmidt CF. The effects of altered arterial tensions of carbon dioxide and oxygen on cerebral blood flow and cerebral oxygen consumption of normal young men. J Clin Invest 1948;27:48492 CrossRef Medline

12. Prohovnik I, Hurlet-Jensen A, Adams R, et al. Hemodynamic etiology of elevated flow velocity and stroke in sickle-cell disease. $J$ Cereb Blood Flow Metab 2009;29:803-10 CrossRef Medline

13. Spano VR, Mandell DM, Poublanc J, et al. CO2 blood oxygen leveldependent MR mapping of cerebrovascular reserve in a clinical population: safety, tolerability, and technical feasibility. Radiology 2013;266:592-98 CrossRef Medline

14. Pillai JJ, Mikulis DJ. Cerebrovascular reactivity mapping: an evolving standard for clinical functional imaging. AJNR Am J Neuroradiol 2015;36:7-13 CrossRef Medline

15. Dlamini N, Shah-Basak P, Leung J, et al. Breath-hold blood oxygen level-dependent MRI: a tool for the assessment of cerebrovascular reserve in children with Moyamoya disease. AJNR Am J Neuroradiol 2018;39:1717-23 CrossRef Medline
16. Markus H, Cullinane M. Severely impaired cerebrovascular reactivity predicts stroke and TIA risk in patients with carotid artery stenosis and occlusion. Brain 2001;124:457-67 CrossRef Medline

17. Gupta A, Chazen JL, Hartman M, et al. Cerebrovascular reserve and stroke risk in patients with carotid stenosis or occlusion: a systematic review and meta-analysis. Stroke 2012;43:2884-91 CrossRef Medline

18. Reinhard M, Schwarzer G, Briel M, et al. Cerebrovascular reactivity predicts stroke in high-grade carotid artery disease. Neurology 2014;83:1424-31 CrossRef Medline

19. Schubert GA, Weinmann C, Seiz M, et al. Cerebrovascular insufficiency as the criterion for revascularization procedures in selected patients: a correlation study of xenon contrast-enhanced CT and PWI. Neurosurg Rev 2009;32:29-35; discussion 35-36 Medline

20. Fierstra J, Maclean DB, Fisher JA, et al. Surgical revascularization reverses cerebral cortical thinning in patients with severe cerebrovascular steno-occlusive disease. Stroke 2011;42:1631-37 CrossRef Medline

21. Smith ER, Scott RM. Moyamoya: epidemiology, presentation, and diagnosis. Neurosurg Clin N Am 2010;21:543-51 CrossRef Medline

22. Rea D, Brandsema JF, Armstrong D, et al. Cerebral arteriopathy in children with neurofibromatosis type 1. Pediatrics 2009;124:e47683 CrossRef Medline

23. Adams RJ, McKie VC, Hsu L, et al. Prevention of a first stroke by transfusions in children with sickle cell anemia and abnormal results on transcranial Doppler ultrasonography. $N$ Engl J Med 1998;339:5-11 CrossRef Medline

24. Fukui M. Guidelines for the diagnosis and treatment of spontaneous occlusion of the circle of Willis ('Moyamoya' disease): Research Committee on Spontaneous Occlusion of the Circle of Willis (Moyamoya disease) of the Ministry of Health and Welfare, Japan. Clin Neurol Neurosurg 1997;99:S238-40 CrossRef Medline

25. Slessarev M, Han J, Mardimae A, et al. Prospective targeting and control of end-tidal $\mathrm{CO} 2$ and $\mathrm{O} 2$ concentrations. J Physiol 2007;581:1207-19 CrossRef Medline

26. Thomason ME, Burrows BE, Gabrieli JD, et al. Breath holding reveals differences in $\mathrm{FMRI} B O L D$ signal in children and adults. Neuroimage 2005;25:824-37 CrossRef Medline

27. Cox RW, Hyde JS. Software tools for analysis and visualization of fMRI data. NMR Biomed 1997;10:171-78 Medline

28. Gold S, Christian B, Arndt S, et al. Functional MRI statistical software packages: a comparative analysis. Hum Brain Mapp 1998;6:73-84 CrossRef Medline

29. Jenkinson M, Beckmann CF, Behrens TE, et al. FSL. Neuroimage 2012;62:782-90 CrossRef Medline

30. Smith SM, Jenkinson M, Woolrich MW, et al. Advances in functional and structural MR image analysis and implementation as FSL. Neuroimage 2004;23(Suppl 1):S208-19 CrossRef Medline

31. Woolrich MW, Jbabdi S, Patenaude B, et al. Bayesian analysis of neuroimaging data in FSL. Neuroimage 2009;45:S173-86 CrossRef Medline

32. Heyn C, Poublanc J, Crawley A, et al. Quantification of cerebrovascular reactivity by blood oxygen level-dependent MR imaging and correlation with conventional angiography in patients with Moyamoya disease. AJNR Am J Neuroradiol 2010;31:862-67 CrossRef Medline

33. Hallemeier CL, Rich KM, Grubb RL Jr, et al. Clinical features and outcome in North American adults with Moyamoya phenomenon. Stroke 2006;37:1490-96 CrossRef Medline

34. Mikulis DJ, Krolczyk G, Desal H, et al. Preoperative and postoperative mapping of cerebrovascular reactivity in Moyamoya disease by using blood oxygen level-dependent magnetic resonance imaging. J Neurosurg 2005;103:347-55 CrossRef Medline

35. Biagi L, Abbruzzese A, Bianchi MC, et al. Age dependence of cerebral perfusion assessed by magnetic resonance continuous arterial spinlabeling. J Magn Reson Imaging 2007;25:696-702 CrossRef Medline

36. Kennedy C, Sokoloff L. An adaptation of the nitrous oxide method to the study of the cerebral circulation in children: normal values for cerebral blood flow and cerebral metabolic rate in childhood. J Clin Invest 1957;36:1130-37 CrossRef Medline 
37. Lin N, Baird L, Koss M, et al. Discovery of asymptomatic moyamoya arteriopathy in pediatric syndromic populations: radiographic and clinical progression. Neurosurg Focus 2011;31:E6 CrossRef Medline

38. Lee S, Rivkin MJ, Kirton A, et al. Moyamoya disease in children: results from the International Pediatric Stroke Study. J Child Neurol 2017;32:924-29 CrossRef Medline
39. Vittinghoff $\mathrm{E}, \mathrm{McC}$ ulloch $\mathrm{CE}$. Relaxing the rule of ten events per variable in logistic and Cox regression. Am J Epidemiol 2007;165:710-18 CrossRef Medline

40. Han JS, Mikulis DJ, Mardimae A, et al. Measurement of cerebrovascular reactivity in pediatric patients with cerebral vasculopathy using blood oxygen level-dependent MRI. Stroke 2011;42:1261-69 CrossRef Medline 